REVIEW

\title{
The management of poor performance
}

John F Mayberry

Postgrad Med J 2007;83:105-108. doi: 10.1136/pgmj.2005.040758

Identification of poor performance is in an integral part of government policy. The suggested approach for the identification of such problems, advocated by the General Medical Council, is that of appraisal. However, traditionally, there has been a reluctance to deal with poor performers, as all doctors have made mistakes and are usually only too ready to forgive and be non-critical of colleagues. The problems are widespread, and $6 \%$ of the senior hospital workforce in any 5 -year period may have problems.

W hen appraising or counselling poorly performing medical students or doctors, it is important to ensure that they have received appropriate education for the work in which they are engaged and that this education is linked with their learning style and takes place in a suitable environment.

The identification of poor performance is an integral part of government policy, as embodied in Supporting doctors, protecting patients. ${ }^{1}$ It should be concerned with how people behave and not who they are. Clearly, any review dealing with the management of poor performance also needs to consider the mechanisms by which that performance is identified. The suggested approach that has been advocated by the General Medical Council for the identification of such problems is that of appraisal. Although poor performance is seen across all professions and industries, medicine carries with it aspects that are specific to the caring professions. Here, poor performance can have direct effects on patient welfare. Despite this, traditionally, there has been a reluctance to deal with poor performers, as all doctors have made mistakes and are usually only too ready to forgive and be non-critical of colleagues. ${ }^{2}$ However, after a series of medical catastrophes in the past century, it is now important that there are robust methods by which poor performers can be identified. These mechanisms need to be paralleled by innovative and adequate methods for motivating and retraining poor performers. Choices should be evidence based, but there is limited scientific work regarding which are the best methods of dealing with such doctors. In practice the approach has been rather different. In a recent survey of senior health professionals involved in the management of medical professional performance, informal discussion, education, training and work shifting were the most usual means of handling a doctor whose performance was poor. ${ }^{3}$ This study also showed that consistent and serious errors in management and outcome were considered to be the most serious deficiencies that constituted poor performance.
Diagnosis and prescription errors were ranked second and third. ${ }^{3}$ Problems with communication skills and manner and attitude were considered less likely to constitute poor performance, although in practice they were the most frequently encountered problems. $^{3}$ This again reflects a reluctance to approach the problem analytically and to use research methods to discover the best ways of dealing with the poor performer in medicine. Other work has suggested that the problems are widespread, and that $6 \%$ of senior hospital workforce in any 5 -year period may have problems. ${ }^{4}$ This clearly shows the need for a more rounded approach to the management of poor performers in medicine. In a subsequent report, the main barriers to managing such a situation included the difficulties created by clinical rotations and the reluctance of doctors to criticise their peers. ${ }^{5}$ National changes in the policing of the profession, as seen with the emergence of the General Medical Council Performance Procedures, gives some urgency to the need for good quality research on motivation and performance issues so that decisions are evidence based rather than political.

\section{THE NEED FOR ADEQUATE EDUCATION}

Academic study of poor performance has received some stimulus from the work of Ginzberg et al. ${ }^{6}$ They investigated the causes of ineffectiveness of almost 73000 American soldiers during the Second World War. They recognised that poor performance was a composite of many facets, which reflected individual differences, responses to stress and the policies of the organisation, in this case the army. ${ }^{6}$ A major factor in poor performance was the level of education. The less educated soldier encountered greater difficulties in keeping pace, tended to fall behind and became emotionally upset. ${ }^{6}$ Adequate education was the overriding prerequisite in this study for effective performance. One aspect of poor performance among doctors is probably a failure to provide adequate and appropriate education for the job in which they are engaged. When appraising or counselling poorly performing medical students or doctors, it is important to ensure that they have received appropriate education for the work in which they are engaged, that this education is linked with their learning style and takes place in a suitable environment. In my personal experience, I have seen this among several sponsored overseas doctors in their first post in the UK. The clinical conditions they are dealing with and the attitude of other staff, such as nurses, is outside their experience. A lack of induction programmes or specific education about clinical practice and multidisciplinary team working in the UK can 
lead to criticism and suspension. The situation is not helped by the "bullying culture" that is widespread in hospitals."

Ginzberg et al's ${ }^{6}$ study drew some useful broader implications, which are particularly relevant as medical workforce expands rapidly in the UK. Selection processes will become less reliable, the need for effective and good quality leadership will be more urgent and a readiness to reassign people to more suitable posts is required. Management needs to behave equitably and not to demotivate its workers. ${ }^{6}$ At a time of management change, the uncertainties surrounding postgraduate training programmes, the movement away from paternalistic firm structures and the status of doctors compared with specialist nurses, there is a need to develop effective programmes to deal with the ineffective doctor. A personal study of the counselling needs of junior doctors has shown that there is a need for support mechanisms, particularly as the traditional firm disappears. Such mechanisms might reduce the number of problem doctors-allowing problems to be dealt with before they affect clinical care or personal welfare.

\section{RECOGNISING THE POOR PERFORMER}

Stewart and Stewart ${ }^{8}$ have provided a checklist to help identify such poor performers. It includes checks on the following:
- Quantity of work
- Quality of work
- Absenteeism
- Role as the centre of conflict
- Dishonesty
- Setting of unrealistic targets
- Refusal to delegate
- Slowness in taking decisions.

Two principal methods for identifying poor performance in these areas have been recognised. They are either reactive or proactive. In the reactive situation, complaints, critical incidents and complaints by colleagues form the basis for an investigation. Such information already exists and is being monitored through clinical governance. By contrast, in the proactive situation, data collected on agreed indicators would form the basis for identifying poor performance (Guildford and Waverley NHS Primary Care Trust Working Draft Framework and Procedure for managing concerns about a doctors performance in general practice). The problem with this approach lies in the fact that there are few nationally agreed indicators. In appraisal, through dialogue with a fellow professional, the appraisees can reflect on their role, compare it with local or national indicators, and consider how it may be improved. It should not be a process of collecting data and filling boxes. Rather, according to Dr David Martin, who developed the process, its purpose is "to have a focused efficient, constructive discussion" (http://www.nhs.uk/nhsmagazine/primarycare/archives/apr2002/coverfeature.asp). Implicit in this approach is that the appraiser should help focus discussions on areas of poor as well as good performance. However, the proposals that are likely to be introduced for the monitoring of the performance of junior doctors on foundation programmes are rather more rigorous and have the quality of formal testing and grading of clinical competence. As a result (see http://www.mmc.nhs.uk/foundation.asp?sector $=$ The\%20Foundation\%20Programme),

The requirements for full registration are likely to change from the current time-based arrangement to one based on the achievement of specific competencies.
Such an approach should limit the initial registration of poor performers, but as a result, there will probably be an increase in the number of junior doctors identified as ineffective and dangerous. Williams and Lau' suggested that the situation may be further exacerbated by current training, which they believed provided students with an inadequate knowledge base and could lead to them being poor clinicians. Once such doctors are identified at the beginning of their career, we will need to have in place mechanisms for remotivating and retraining them. Unfortunately, these do not seem to exist at present, and there is little organised research on investigating the best mechanisms for dealing with poor performance at such an early stage in a doctor's career.

\section{MODELS OF POOR PERFORMANCE}

Psychologists have attempted to construct models that could help in providing some understanding of what motivates and demotivates people. Maslow ${ }^{10}$ constructed a hierarchy of need with basic physiological necessities, such as food and water, at the bottom of the pyramid (fig 1). In this model, the need for status and growth can only be realised once an individual's other needs have been met. It is particularly valuable for considering people at the lower levels, but tends to be excessively individualistic, and does not allow for altruism. However, concerns about safety, social issues and status can be particularly important for doctors. A failure to pass critical examinations can be a career block, and lead to lowered selfesteem with an inability to grow and develop. In addition, such a failure can be a threat to security, with a reduced ability to obtain a new post or continue in the career to which the doctor had aspired (http://www.dmu.ac.uk/ jamesa/learning/ motivlrn.htm\#Levels\%20of\%20Motivation). By contrast, Herzberg ${ }^{11}$ suggested a model (fig 2) in which the conditions at work were the drivers for performance and he divided these into motivators and demotivators (http://www.dmu.ac.uk/ 〜jamesa/learning/motivlrn.htm\#Levels\%20of\%20Motivation). This model has more direct relevance to clinicians, particularly in times of change. Many doctors now experience continual pressure, poor working conditions and feelings of isolation.

During the appraisal of a poor performer, the identification of problems in these areas may provide an explanation for their performance. They could, for example, be due to cultural differences that can be a contributory factor to feelings of isolation for some doctors. In contrast with these problems and other issues such as ill health, if the appraisee is able to do the job, but simply will not do it, this is an issue of conduct rather than capability. ${ }^{12}$ It should become the subject of disciplinary action rather than of counselling and retraining. However, it is possible that if a job plan is inadequate, then the doctors may not be aware of what their role is, and this could be a reason for

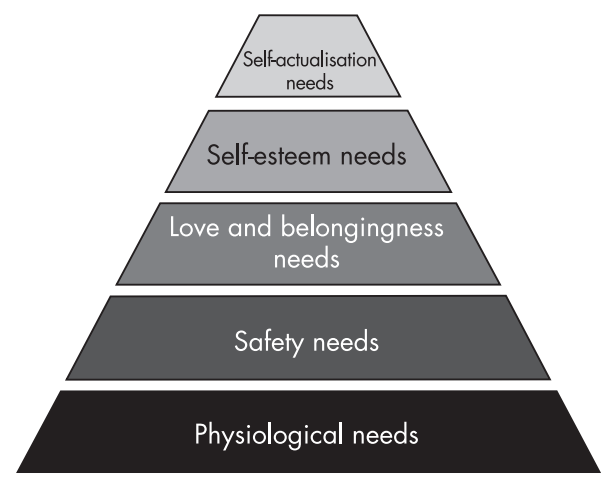

Figure 1 Maslow's "hierarchy of needs", currently unsatisfied, but thought needs are motivators. ${ }^{10}$ 


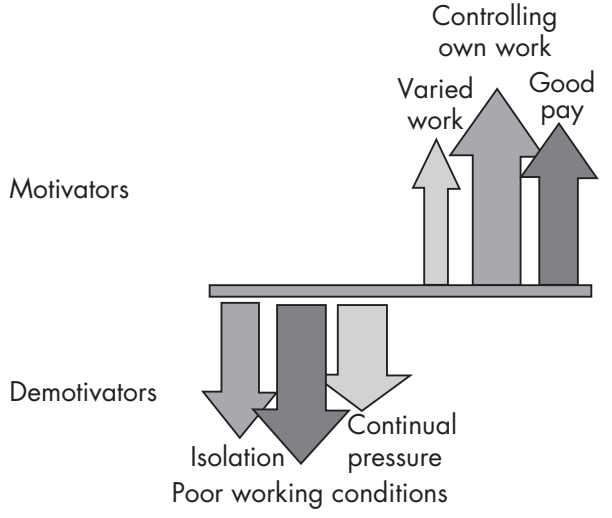

Figure 2 Herzberg's motivational hygiene model."

failing to perform adequately. In addition, one of the difficulties in considering the management of poor performers is to identify sources of evidence that confirm the benefits of pastoral, educational or disciplinary interventions. Much of the published work is almost anecdotal in nature and its value has seldom been assessed. However, Pendleton's model for giving feedback can certainly be applied to the poorly performing doctor, particularly when dealing with specific tasks. $^{13}$

\section{A PRACTICAL APPROACH}

One approach is to combine all three elements into a professional discussion with the poor performers. ${ }^{12}$ In such a discussion, the nature of the problem needs to be set out in specific terms. This could include a comparison of operative infection rates between the poor performers and their colleagues, either within the hospital or outside it. Use of such hard data allows the setting of measurable targets for the poor performers to achieve after they have been through some support process. This process needs to identify the causes of poor performance and the mechanisms of retraining, which can address underlying deficiencies in the appraisee's practice. This may include the following:

- Agreement on the size of the problem

- Individual mentoring and support

- Development of learning plans

- Tutorials with an experienced colleague

- In-house or external training

- Regular review of progress

- Good documentation of these activities.

Having identified the problems that constitute poor performance, counselling theory advocates dealing with the behaviour rather than the personality. ${ }^{8}$ It is easier for the underperformers to change their behaviour than to change their personality. It permits discussions about what has gone wrong while still having a basic acceptance and regard for the underperformers. ${ }^{8}$ The process needs to identify standards by which to assess progress and a timetable in which to achieve it.

When there is lack of agreement or a failure to achieve agreed objectives, it is eventually necessary to consider a change in post, but this will require specific career counselling. However, changing posts carries with it the risk of simply passing on the problem and not dealing with it. In my experience of working with junior doctors, this is a common approach, and the problem usually recurs in the next hospital or deanery. When possible, an alternative method would be to redevelop the person's current post. This could take several formats. It may mean reducing the stress of shift work or travelling long distances to a hospital that is part of a training rotation, or, if in an established post, the appraisees may need to find new challenges so that they continue to grow and develop as in the Maslow model. Such job redesign, when carried out together with the poor performer, can make the post more attractive, lengthen the learning curve and provide variety. ${ }^{8}$

However, in some cases, the problem is one that can be addressed only through training. Management theory would suggest that the training programme should not include within it an assessment of the poor performers, as this will limit their willingness to learn those very things for which they have been sent on the course. ${ }^{8}$ It should, however, meet the requirements of any well-planned educational programme, and for adult learners, as suggested by Mohanna et al, ${ }^{13}$ needs to take their views into account. Unfortunately such an approach has to be compared with that now advocated for poor performers in medicine in the UK:

The GMC [General Medical Council] Performance Procedures are a unique development in a critical environment. In addition to establishing the facts, the combination of assessment of performance in the workplace with tests of competence that confirm and explain the assessors' findings, allows a comprehensive diagnosis of the causes of poor performance. In turn this establishes the basis for a realistic recommendation for remedial action. As far as we are aware no other health profession has introduced such robust measures for the protection of the public from its poorly performing practitioners. ${ }^{14}$

Although the intention is to use such an assessment to form the basis for remedial action, the details of such retraining programmes have yet to be published, and require as much, if not more than, the performance procedures. Again this system has been introduced without rigorous assessment of its effectiveness or of its effect on improved performance. Perhaps the fact that no other professional group is using this technique should lead to some caution and reflection before its widespread introduction.

Formal assessment of performance in the UK is to be based on the Cambridge model, which is a modification of Miller's pyramid. This model identifies performance as a product of competence, the influences of the individual such as health and relationships, and the influences of the system such as facilities and workload. It helps to separate competence from actual performance. ${ }^{15}$

In summary, the poor performers are of concern to their colleagues and a potential threat to patients. Mechanisms for their identification are now being introduced on a national level through assessment for junior doctors and appraisal for senior clinicians. However, remedial retraining is not well established and there has been little research on its effectiveness. The evidence for management of retraining comes largely from the world of management, and lacks scientific rigour as to its effect on outcome. Through managing poor performers, can we make them adequate or good doctors?

Competing interests: None declared.

\section{REFERENCES}

1 Anon. Supporting doctors, protecting patients, A consultation paper on preventing, recognising and dealing with poor clinical performance of doctors in the NHS in England. London, 1999.

2 Smith R. All doctors are problem doctors. BMJ 1997;314:841. 
3 Hutchinson A, Williams M, Meadows RS, et al. Perceptions of good medical practice in the NHS: a survey of senior health professionals. Qual Health Care 1999;8:213-18

4 Donaldson $\amalg$. Doctors with problems in an NHS workforce. BM 1994:308:1277-82.

5 Hutchinson A, Mclntosh A, Williams M, et al. Senior health professional's perceptions of variations in medical practice: a qualitative and quantitative study. Med Educ 2001;35(Suppl 1):45-51.

6 Ginzberg E, Anderson JK, Ginsburg SW, et al. Patterns of Performance, New York: Columbia University Press, 1959.

7 Quine L. Workplace bullying in junior doctors: questionnaire survey. BMJ 2002;324:878-9

8 Stewart V, Stewart A. Managing the poor performer. Aldershot, UK: Gower Publishing, 2002.
9 Williams G Lau A. Reform of undergraduate medical teaching in the United Kingdom: a triumph of evangelism over common sense. BMJ 2004;329:92-4 10 Maslow A. Motivation and personality, New York: Harper and Row, 1987.

11 Herzberg F. Work and the nature of man, Cleveland: World Publishing, 1966.

12 Cooper M. Curtis B. Managing poor performance handling staff capability issues, Stafford: Network Educational Press, 2000

13 Mohanna K, Wall D, Chambers R. Teaching made easy. A manual for health professionals, Oxford: Radcliffe Press, 2004.

14 Southgate L, Cox J, David T, et al. The assessment of poorly performing doctors: the development of the assessment programmes for the General Medical Council's Performance Procedures. Med Educ 2001;35(Suppl 1):2-8.

15 Rethans JJ, Norcini JJ, Baron-Maldonado M, et al. The relationship between competence and performance: implications for assessing practice performance. Med Educ 2002;36:901-9.

\section{Clinical Evidence-Call for contributors}

Clinical Evidence is a regularly updated evidence-based journal available worldwide both as a paper version and on the internet. Clinical Evidence needs to recruit a number of new contributors. Contributors are healthcare professionals or epidemiologists with experience in evidence-based medicine and the ability to write in a concise and structured way.

Areas for which we are currently seeking contributors:

- Pregnancy and childbirth

- Endocrine disorders

- Palliative care

- Tropical diseases

We are also looking for contributors for existing topics. For full details on what these topics are please visit www.clinicalevidence.com/ceweb/contribute/index.jsp

However, we are always looking for others, so do not let this list discourage you.

Being a contributor involves:

- Selecting from a validated, screened search (performed by in-house Information Specialists) epidemiologically sound studies for inclusion.

- Documenting your decisions about which studies to include on an inclusion and exclusion form, which we keep on file.

- Writing the text to a highly structured template (about 1500-3000 words), using evidence from the final studies chosen, within 8-10 weeks of receiving the literature search.

- Working with Clinical Evidence editors to ensure that the final text meets epidemiological and style standards.

- Updating the text every 12 months using any new, sound evidence that becomes available. The Clinical Evidence in-house team will conduct the searches for contributors; your task is simply to filter out high quality studies and incorporate them in the existing text.

If you would like to become a contributor for Clinical Evidence or require more information about what this involves please send your contact details and a copy of your CV, clearly stating the clinical area you are interested in, to CECommissioning@bmigroup.com.

\section{Call for peer reviewers}

Clinical Evidence also needs to recruit a number of new peer reviewers specifically with an interest in the clinical areas stated above, and also others related to general practice. Peer reviewers are healthcare professionals or epidemiologists with experience in evidence-based medicine. As a peer reviewer you would be asked for your views on the clinical relevance, validity, and accessibility of specific topics within the journal, and their usefulness to the intended audience (international generalists and healthcare professionals, possibly with limited statistical knowledge). Topics are usually 1500-3000 words in length and we would ask you to review between 2-5 topics per year. The peer review process takes place throughout the year, and out turnaround time for each review is ideally 10-14 days.

If you are interested in becoming a peer reviewer for Clinical Evidence, please complete the peer review questionnaire at www.clinicalevidence.com/ceweb/contribute/peerreviewer.jsp 